\title{
Preliminary proposal of scientific data verification in CSES mission
}

\author{
Lan-wei Wang $\cdot$ Xu-hui Shen $\cdot$ Yu Zhang $\cdot$ Rui Yan
}

Received: 15 May 2015/ Accepted: 20 July 2015/Published online: 2 September 2015

(C) The Author(s) 2015. This article is published with open access at Springerlink.com

\begin{abstract}
China Seismo-Electromagnetic Satellite (CSES) will be launched at the end of 2016 and the orbit is sunsynchronous and the altitude is about $500 \mathrm{~km}$. The design of CSES satellite and ground segment are introduced in this paper first. And then the preliminary proposals of scientific data verification and cross-verification in CSES mission are given, which can be used to classify the payloads' operation state, and validate the reliability of data.
\end{abstract}

Keywords CSES mission - Data verification - Intercalibration

\section{Introduction}

\subsection{The CSES mission}

China Seismo-Electromagnetic Satellite (CSES) is the first experimental satellite for earthquake-related electromagnetic emission monitoring from ionosphere, which make technical preparation for a future satellite monitoring system in China (Shen et al. 2011). The main missions of CSES include

L. Wang $\cdot$ X. Shen $\cdot$ Y. Zhang $(\bowtie) \cdot$ R. Yan

Institute of Crustal Dynamics, China Earthquake Administration,

Beijing 100085, China

e-mail: zyflyingfish@163.com

L. Wang

e-mail: wanglw829@126.com

L. Wang $\cdot$ Y. Zhang $\cdot$ R. Yan

Beijing Engineering Research Center of Earthquake

Observation, Beijing 100085, China
(1) Measurement of signals from electromagnetic emission and its disturbances in ionosphere;

(2) Measurement of background magnetic field in space;

(3) Measurement of the disturbance of plasma in ionosphere, such as contents, density and temperature of the ions, density and temperature of the electron, total electron contents, etc.;

(4) Measurement of energetic particles precipitation.

The satellite platform of CSES was redesigned based on the CAST-2000 platform with eight payloads onboard, namely search coil magnetometer, electric field detector, fluxgate magnetometer, global navigation satellite system (GNSS) occultation receiver, plasma analyzer (PA), Langmuir probe (LP), Tri-band beacon (TBB), and high energetic particle detector. Figure 1 shows the layout of CSES satellite. The payloads and its main specifications are shown in Table 1.

In order to achieve high accuracy electromagnetic field detection, many strict electromagnetic compatibility (EMC) methods were used for the satellite platform and payloads to avoid interference. There are two different working zones separated by geo-location, one is the payload working zone, the other is the platform adjustment zone. The latitude of payload working zone is from $-65^{\circ}$ to $65^{\circ}$, in which there is no rotation of solar panel and no action for attitude and orbit control system (AOCS) of satellite. The latitude of platform adjustment zone is larger than $65^{\circ}$ or less than $-65^{\circ}$, in which all the payloads will stop working.

All the payloads have two operating modes: "burst mode" and "survey mode." The burst mode is usually operated only when the satellite passes over whole China territory, its neighboring area, and the regions with the strongest seismic activities in the world. The survey mode is operated for other areas of the Earth. The two modes will be adopted for all on-board payloads. 


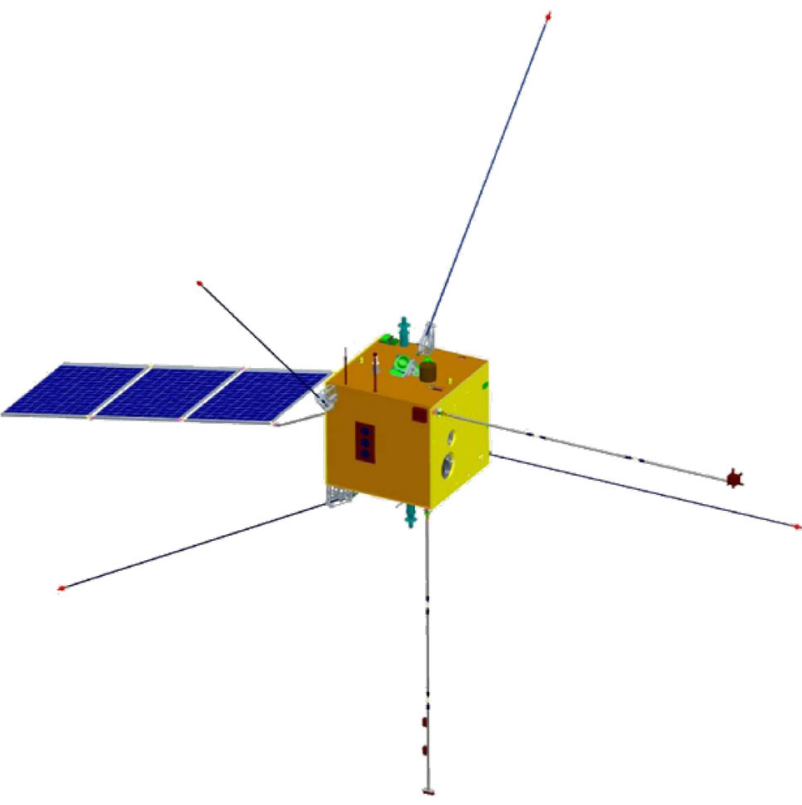

Fig. 1 Layout of CSES satellite

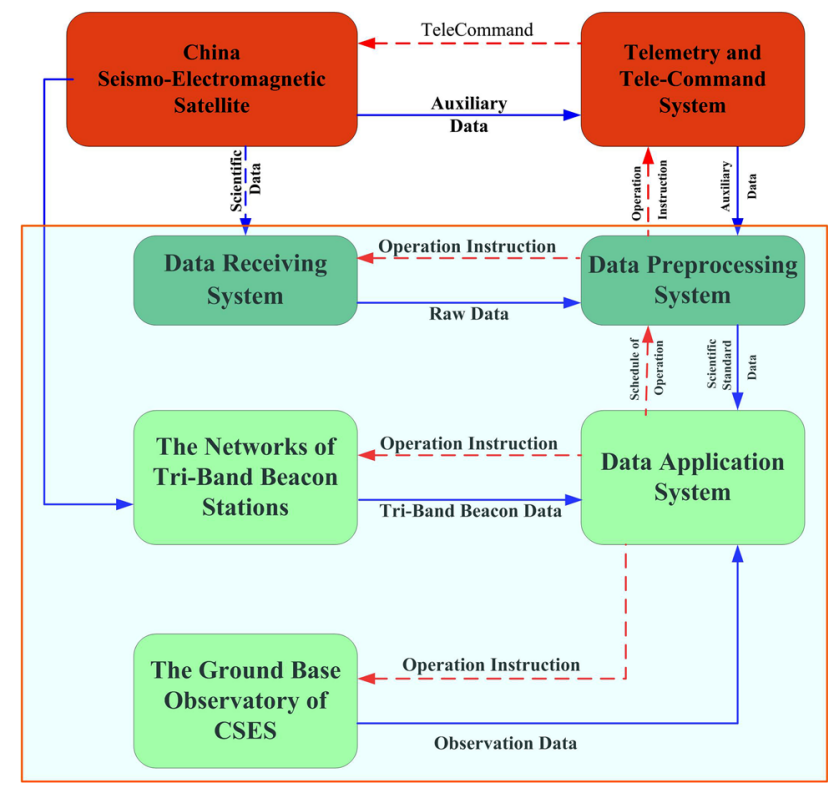

Fig. 2 Ground segment architecture of CSES
Table 1 Payloads and observation targets of CSES satellite

\begin{tabular}{|c|c|c|}
\hline Category & Payloads & Specifications \\
\hline ElectroMagnetic field & $\begin{array}{l}\text { Electric field detector } \\
\text { High precision magnetometer } \\
\text { Search coil magnetometer }\end{array}$ & $\begin{array}{l}\text { Electric field: DC-3.5 MHz } \\
\text { Magnetic field: DC- } 15 \mathrm{~Hz} \\
\text { Magnetic field: } 10-20 \mathrm{kHz}\end{array}$ \\
\hline In-situ plasma & Plasma analyzer package & $\begin{array}{l}\text { Composition: } \mathrm{H}^{+}, \mathrm{He}^{+}, \mathrm{O}^{+} \\
N_{\mathrm{i}}: 5 \times 10^{2}-1 \times 10^{7} \mathrm{~cm}^{-3} \\
T_{\mathrm{i}}: 500-10,000 \mathrm{~K} \\
N_{\mathrm{e}}: 5 \times 10^{2}-1 \times 10^{7} \mathrm{~cm}^{-3} \\
T_{\mathrm{e}}: 500-10,000 \mathrm{~K}\end{array}$ \\
\hline Plasma construction & $\begin{array}{l}\text { GNSS occultation receiver } \\
\text { Tri-band beacon }\end{array}$ & $\begin{array}{l}\text { TEC by GNSS occultation signal } \\
\text { TEC by transmit VHL/U/L Signal }\end{array}$ \\
\hline Energetic particle & High energy particle package & $\begin{array}{l}\text { Proton: 2-200 MeV } \\
\text { Electron: } 100 \mathrm{keV}-50 \mathrm{MeV}\end{array}$ \\
\hline
\end{tabular}

\subsection{Ground segment and data products}

The ground segment of CSES includes data receiving system and data application system. Figure 2 is the ground segment architecture of CSES.

\subsubsection{Data receiving system}

The data receiving system was designed to fulfill the task of data receiving, data management, data preprocessing, and data transferring to data application system.

The data receiving system include five data receiving stations (Beijing, Mudanjiang, Kashgar, Sanya, and Kunming). It has the ability to receive, preprocess, and manage the real time and non-real time monitoring data of the electromagnetic field and ionosphere all over the world.

\subsubsection{Data application system}

According to the requirement of satellite's application and scientific objectives, the main tasks of CSES data application system are as follows:

(1) To fulfill the operation and manage requirements of CSES.

(2) To verify and evaluate the data from the satellite.

(3) To process the data and produce different level data according to the scientific data processing level. 
(4) To extract the electromagnetic information possibly associated with the earthquakes of $M_{\mathrm{S}} \geq 6$ within China and its neighboring area and that of $M_{\mathrm{S}} \geq 7$ in the global scale. In order to test the possibility for short-term earthquake forecasting experimentally in terms of satellite observation.

(5) To study the lithosphere-atmosphere-ionosphere (LAI) coupling mechanism using CSES data.

(6) To provide data sharing for other scientific research, such as space weather, meteorology, aerospace, navigation, and communication.

\subsubsection{Data products}

The data products of CSES are classified into raw data, scientific data of different level, and earthquake case study data. The main types of data are as follows:

(1) Multi-band waveform and spectrum of electromagnetic field;

(2) In-situ plasma parameters including electron and ion density and temperature;

(3) Electron density profiles and tomography;

(4) Energetic particle flux and energy spectra;

(5) Case study results associated with earthquakes with magnitude larger than $M_{\mathrm{S}} 6$ in China and larger than $M_{\mathrm{S}} 7$ around the world;

(6) Geomagnetic field model, ionosphere model, as well as other related scientific research products.

\section{The reliability of CSES data}

The main purpose of CSES mission is to detect the abnormal electromagnetic information related to earthquakes. The reliability of data is the most important. But it is impossible to tell whether the observation data are reliable or not only by the data itself.

Fortunately, according to the previous study result, in the extremely low frequency (ELF) and very low frequency (VLF) domains, mostly atmospheric and ionospheric perturbations of the EM field are observed from ground networks (Gokhberg et al. 1982; Hayakawa 1999; Pulinets 2004; Kopytenko et al. 2004) and on board of satellites (Parrot 1994; Liu et al. 2004).

Figure 3 shows the diagrammatic representation of abnormal EM signal emission and its propagation. It shows that the abnormal EM signal, possibly related to earthquakes, will travel along the magnetic field lines and can be detected by the satellite.

So, there are two methods that can be used to do data verification and satellite payloads state judgment. One is

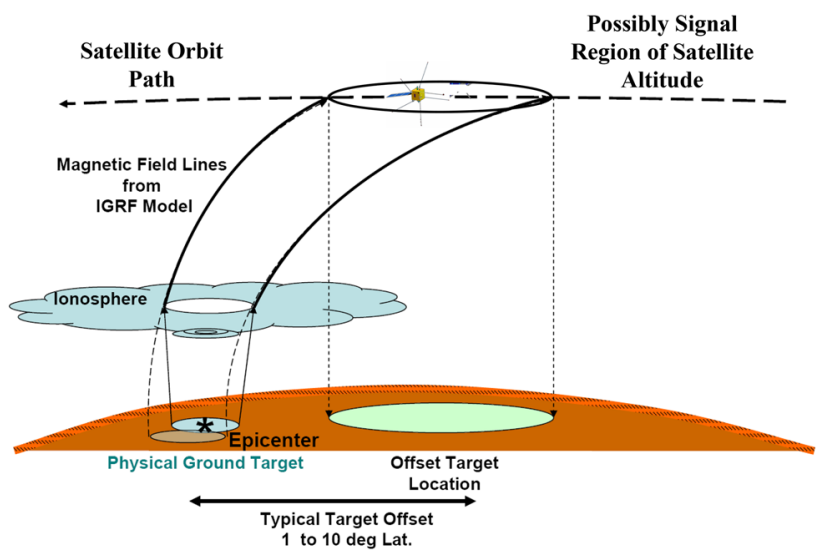

Fig. 3 Diagram of abnormal EM signal emission and its propagation

comparing CSES data with ground-based electromagnetic observed data, which was called comparison observation; the other is comparing CSES data with other satellites scientific data, which was called cross-verification. So a ground-based observation system was designed to help detect earthquake-related signals on the ground and validate the satellite observation data.

For the ground comparison observation, we can use ultra-low frequency (ULF) electromagnetic observation, ionosphere vertical sounding, and incoherent scattering radar observation data. (Zhu and Wang 2011; Cutler et al. 2008; An et al. 2011)

For the cross-verification, we can compare the scientific data from different payloads in CSES and compare the data from CSES with that from other similar satellites, such as SWARM satellite.

\section{Ground comparison observation}

\subsection{Design of ground-based observation system of CSES}

The main objectives of ground-based observation system are to detect earthquake-related signals on the ground, and to compare and validate EM observations from satellite.

\subsubsection{Observatory sites}

The strategy for the sites selection of an observatory is as follows: (a) Close to epicenter fault so that to improve the likelihood of measurements abnormal signals of an earthquake, especially the strong ones. (b) With sensitive to the electromagnetic perturbation. (c) The area of ground-based observation system is about $500 \mathrm{~km} \times 500 \mathrm{~km}$. (d) the distance between two stations is about $50 \mathrm{~km}$, and can not exceed $100 \mathrm{~km}$. 
Figure 4 shows the distribution of $M_{\mathrm{S}}>5.0$ earthquakes in China from 1900 to 2008. Tianzhu area in Gansu province (northeast of Tibet plateau) was selected as the region of the ground-based observation system of CSES. In history, several strong earthquakes took place in this area, such as Haiyuan $M_{\mathrm{S}} 8.5$ earthquake in 1920 , Gulang $M_{\mathrm{S}} 8.0$ earthquake in 1927, Menyuan $M_{\mathrm{S}} 6.4$ earthquake in 1984, and Jingtai $M_{\mathrm{S}} 6.9$ earthquake in 1990 , etc. Now, according to the seismologist's opinion, this area has a potentially higher probability to occur large earthquakes in the next few years.

The location of the ground-based observation system of CSES is shown in Fig. 5. The network is composed of fifteen monitoring stations. All the observatories are deployed along the path of the satellite, and the distance between the two adjacent observatories is about $50-100 \mathrm{~km}$.

\subsubsection{Configuration of observation system}

Ground-based observation system includes electromagnetic field observation and ionospheric parameter observation.

The electromagnetic field observation system includes geo-electric field (DC-0.1 Hz), geomagnetic field (DC$15 \mathrm{~Hz}$ ), low frequency electromagnetic disturbance $(0.1-10 \mathrm{~Hz})$, and high frequency electromagnetic disturbance $(10-100 \mathrm{~Hz})$. Ionospheric parameter observation system includes GNSS, ionosphere vertical sounding, and incoherent scattering radar observation. The measurement components are shown in Table 2.

\subsection{Ground-based electromagnetic observation}

The purpose of the ground-based electromagnetic observation is not only used for comparison with satellite data but also for earthquake prediction system. The groundbased observatories were designed to provide detailed measurements of ULF geo-electric and magnetic field to monitor abnormal ULF information related to earthquake. A data center will be developed to support the operation of all these observatories and to collect and analyze the data.

The proposed electro-geomagnetic observation system is shown in Fig. 6. The system was composed of four modules, which were used for the observation of geoelectric field, geomagnetic field, and electromagnetic perturbation in different frequency ranges (Table 3).

As shown in Fig. 6a, c, d, the measurement electrodes for the electric field measurement are deployed in the northsouth $(\mathrm{N}-\mathrm{S})$, east-west $(\mathrm{E}-\mathrm{W})$ directions, respectively. In Fig. $6 \mathrm{~b}, \mathrm{H}$ and $\mathrm{Z}$ represent the horizontal component and vertical component of geomagnetic field, while $\mathrm{D}$ represents the declination of geomagnetic field. In Fig. 6c, d, there are two induction coil magnetometers, which are oriented in the north, east directions, respectively.

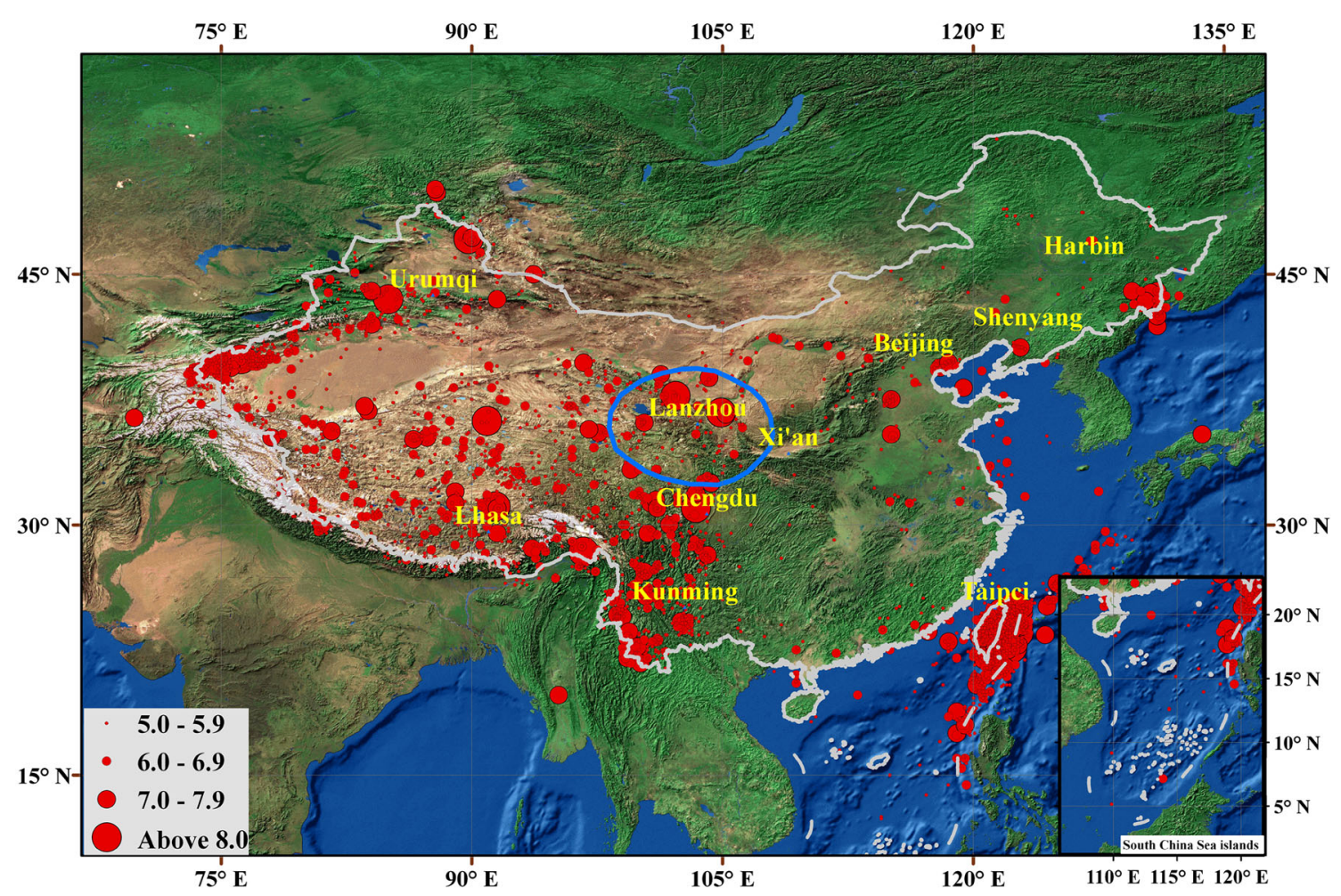

Fig. 4 Distribution of $M_{\mathrm{S}}>5.0$ Earthquakes in China (1900-2008). The blue ellipse is studied area 


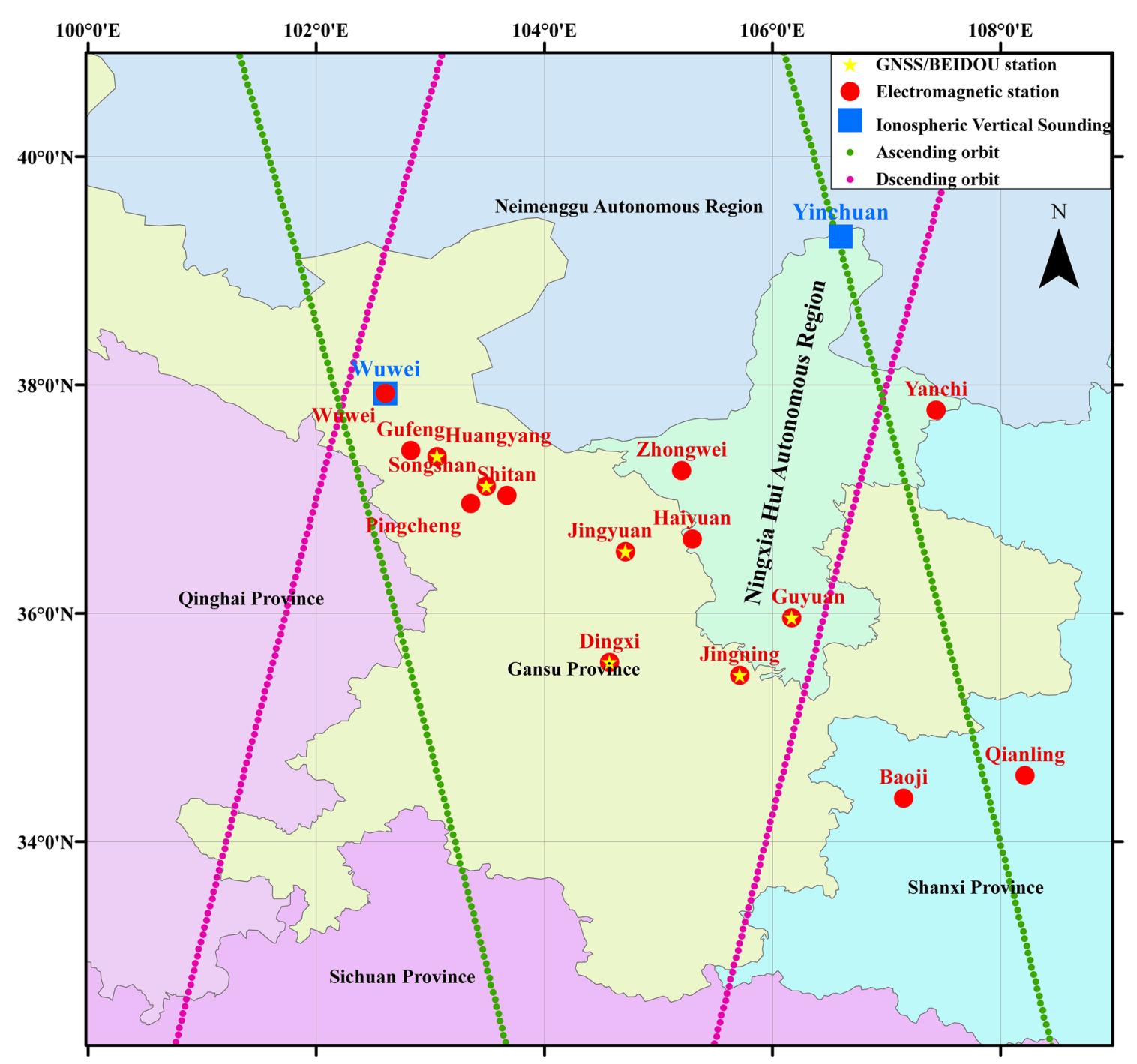

Fig. 5 Design of ground-based observation system of CSES. The blue ellipse is studied area

Table 2 Ground-based observation system

\begin{tabular}{lllll}
\hline & Physics parameter & Frequency range & Measurement component & $\begin{array}{l}\text { Number of } \\
\text { observatories }\end{array}$ \\
\hline Electromagnetic & Geo-electric field & DC-0.1 Hz & $\begin{array}{l}\text { two-horizontal components } \\
\text { One-vertical component }\end{array}$ & 15 \\
& & & three-components & 15 \\
& Geomagnetic field & DC-15 Hz & Geo-electrical field and magnetic field fluctuation & 15 \\
& Electromagnetic disturbance & $0.1-10 \mathrm{~Hz}$ & three-components & 2 \\
& (Induction coil magnetometer) & $10-300 \mathrm{~Hz}$ & NmF (Maximum electron density) & 6 \\
Ionosperic parameter & Ionospheric vertical sounding & & Total electron content (TEC) & Ion temperature, electron density and temperature \\
& GPS/BEIDOU & & &
\end{tabular}

\subsection{Ionosphere vertical sounding}

The most commonly used method to validate the ionospheric measurement data from satellite is by ionospheric model or ionospheric vertical sounding and incoherent scattering radar (ISR) observation data.

Basic ionosphere vertical sounding variables include ionosphere critical frequency of $\mathrm{E}, \mathrm{F}_{1}, \mathrm{~F}_{2}$, Es Layer and 

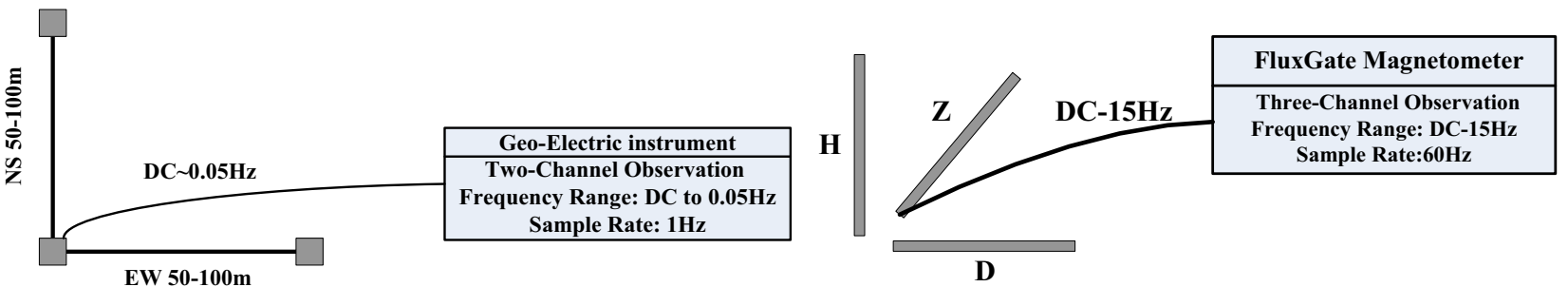

A

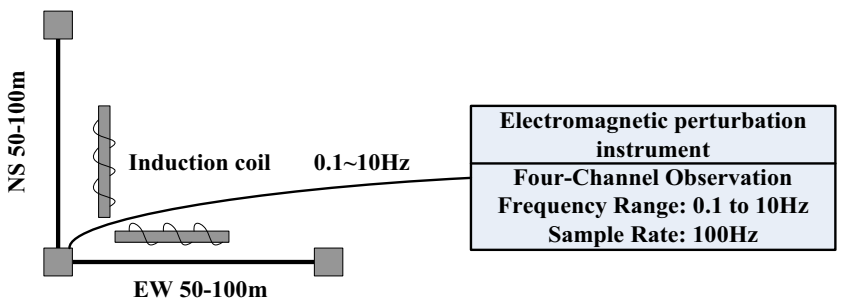

C

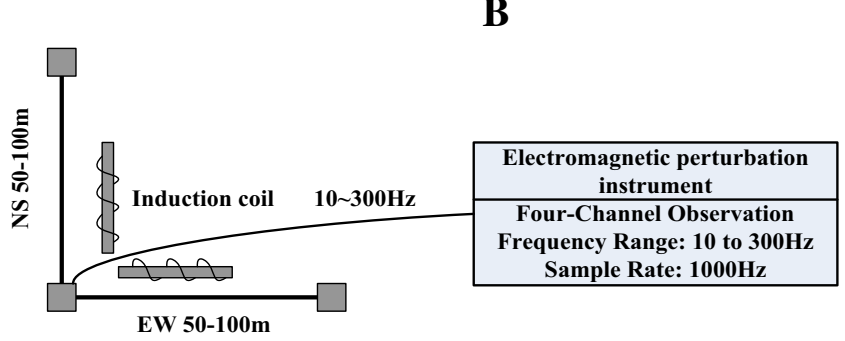

D

Fig. 6 Block diagram of ground-based electromagnetic observation system. a DC- $0.1 \mathrm{~Hz}$ geo-electric field observation. b DC- $15 \mathrm{~Hz}$ geomagnetic field observation. c $0.1-10 \mathrm{~Hz}$ electromagnetic perturbation. d $10-300 \mathrm{~Hz}$ electromagnetic perturbation

Table 3 Payloads and specifications of SWRAM and CSES

\begin{tabular}{|c|c|c|c|}
\hline \multicolumn{2}{|l|}{ SWRAM } & \multicolumn{2}{|l|}{ CSES } \\
\hline Payload & Specifications & Payload & Specifications \\
\hline $\begin{array}{l}\text { Absolute scalar } \\
\text { magnetometer }\end{array}$ & Dynamic range: $15,000-65,000 \mathrm{nT}$ & $\begin{array}{l}\text { HPM (Scalar } \\
\text { magnetometer) }\end{array}$ & Dynamic range: $20,000-100,000 \mathrm{nT}$ \\
\hline Vector field Magnetometer & $\begin{array}{l}\text { Frequency range: } \mathrm{DC}-4 \mathrm{~Hz} \\
\text { Dynamic range: }-65,000 \text { to } 65,000 \mathrm{nT}\end{array}$ & $\begin{array}{l}\text { HPM (Fluxgate } \\
\text { magnetometer) }\end{array}$ & $\begin{array}{l}\text { Frequency range: } \mathrm{DC}-15 \mathrm{~Hz} \\
\text { Dynamic range: }-65,000 \text { to } 65,000 \mathrm{nT}\end{array}$ \\
\hline \multicolumn{2}{|c|}{ Electrical field instrument (EFI) } & \multicolumn{2}{|l|}{ PA } \\
\hline IDM & Ion velocity & IDM & Drift velocity \\
\hline RPA & Ion composition and temperature & RPA & Ion composition, temperature and density \\
\hline LP & Electron density and temperature & LP & Electron density and temperature \\
\hline
\end{tabular}

electron density profile with altitude. The data obtained from CSES mission, which derived from GNSS and TBB, can be compared and analyzed with those from ionospheric vertical sounding.

When doing the data comparison, we can select the data from CSES when the satellite flies over the scope of 10 degrees from ionosphere vertical sounding stations.

\subsection{Incoherent scattering radar (ISR)}

The detection altitude of ISR is from 80 to $6000 \mathrm{~km}$ (typically altitude is $600-1000 \mathrm{~km}$ ). The data, such as electron density profiles, ion temperature, electron density, and temperature obtained from CSES mission (derived from plasma analyzer, Langmuir probe, GNSS, and TBB), can be compared and analyzed with those derived from ISR.
Because of high energy consumption and high cost of ISR, there are only 14 ISR stations in the world (Fig. 7).

In China, a new ISR has been constructed in 2014 in Yunan province. All these resources can be used for the data verification of CSES.

Using ISR to detect F layer, the estimate error of the electron density, electron temperature, and ion temperature is about $5 \%-10 \%$ or less; neutral component error is about $10 \%$; drift velocity measurement precision is about $1-10 \mathrm{~m} / \mathrm{s}$ (Chong et al. 2013).

ISR could be able to detect the electron concentration which is above $F_{2}$ layer peak height. Compared with ionospheric vertical sounding, it has more wide detection range and higher detection precision. The observation targets, such as electron density, electron temperature, ion temperature, and electron density profile can be used to verify the data of CSES. 


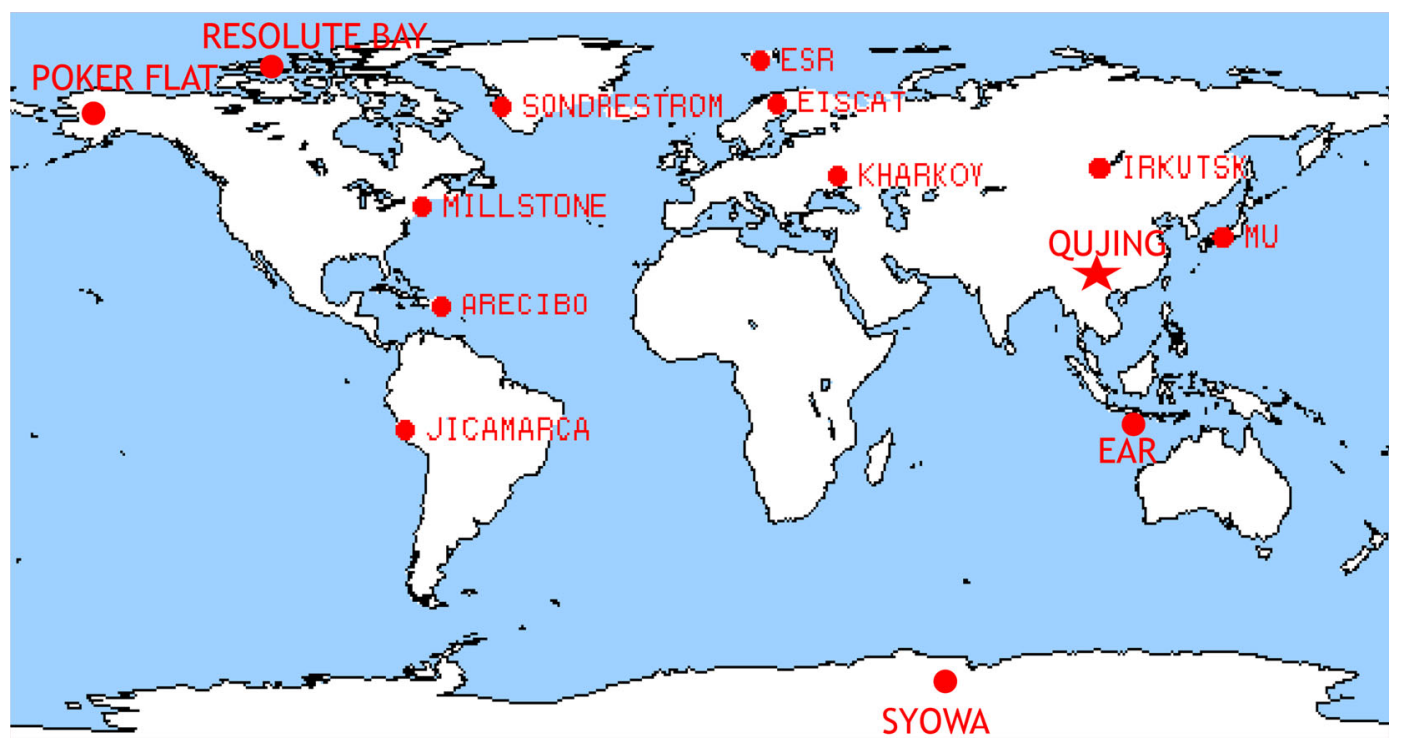

Fig. 7 Global ISR network. Red solid circles stand for ISR stations and the star for a new ISR station in China

\section{Cross-verification}

\subsection{Scientific data from different payloads}

The in-situ measurement of the ionospheric parameters is from PA and LP. PA provides a nearly continuous survey of the main parameters of the thermal ion population. A set of two Langmuir probes measure the electron density and temperature (Maha Quassim 2008).

The total ion and electron density ( $\mathrm{Ni}$ and $\mathrm{Ne}$ ) recorded by PA and LP should be matched for the selected orbits, and they are consistent with the disturbance response in the same space and time. Long-time series data make it possible to perform comparative analysis to search for variation in the regular behavior and correlations between LP and PA.

\subsection{Scientific data from different satellites}

SWARM is a European Space Agency (ESA) mission consisting of three low-Earth orbiting satellites designed specifically to measure magnetic and electric fields. It was launched in late 2013 (Macmillan and Olsen 2013; Haagmans 2001).

The objective of the SWARM mission is to survey the geomagnetic field and its temporal evolution and hence improve our understanding of the Earth's interior and the relation with its environment. There are five scientific payloads on board, namely absolute scalar magnetometer (ASM), vector field magnetometer (VFM), electrical field instrument (EFI), accelerometer (ACC), and laser retro reflector (LRR).

The altitude of SWARM and CSES is very similar. For SWARM constellations, two lower satellites fly at a
$450 \mathrm{~km}$ nominal altitude in near identical orbits, separated by $15 \mathrm{~s}$ in time at their equatorial crossing, while the third flies in a higher orbit at about $530 \mathrm{~km}$. CSES satellite will fly at about $500 \mathrm{~km}$ altitude. So the correlation and the similarity of data obtained by the 2 missions in the near spatial location can be compared directly.

\section{Conclusions}

This is the preliminary proposal for the CSES data verification. It will be very helpful to ensure the reliability of CSES data. Satellite data cross-verification is a still new research field for us, therefore more further studies are needed. We would like to express our sincere wishes to the scientists from all over the world who would participate in the collaboration for the data verification of CSES.

In the future, the ground-based electromagnetic observatories of CSES set up on Tianzhu area will allow us to study the abnormal phenomena related to earthquakes in detail, and the mechanism of the propagation of the earthquake-related EM signals.

Acknowledgments We are grateful to all colleagues who involved in the data verification research of CSES project. This work is supported by the civil space project "CSES Scientific Data Verification Technology Research" and National Natural Science Foundation of China (granted No. 41374127).

Open Access This article is distributed under the terms of the Creative Commons Attribution 4.0 International License (http://crea tivecommons.org/licenses/by/4.0/), which permits unrestricted use, distribution, and reproduction in any medium, provided you give appropriate credit to the original author(s) and the source, provide a link to the Creative Commons license, and indicate if changes were made. 


\section{References}

An ZH, Du XB, Fan YY, Liu J, Tan DC, Chen JY, Xie T (2011) A study of the electric field before the Wenchuan 8.0 earthquake of using both space-based and ground-based observational data. Chin J Geophys 54(11):2876-2884. doi:10.3969/j.issn.00015733.2011.11.017 (in Chinese with English abstract)

Chong XY, Zhang ML, Zhang SR et al (2013) An investigation on plasmaspheric electron content derived from ISR and GPS observations at Millstone Hill. Chin J Geophys 56(3):738-745. doi:10.6038/cjg20130303 (in Chinese with English abstract)

Cutler J, Bortnik J, Dunson C, Doering J, Bleier T (2008) CalMagNet — an array of search coil magnetometers monitoring ultra low frequency activity in California. Nat Hazards Earth Syst Sci 8:359-368

Gokhberg MB, Morgounov VA, Yoshino T, Tomizawa I (1982) Experimental measurement of electromagnetic emissions possibly related to earthquakes in Japan. J Geophys Res 87: 7824-7828

Haagmans R (2001) Swarm: the Earth's magnetic field and environment explorers. ESA SP-1279(6). ESA Publications Division, pp 13-26

Kopytenko E, Kopytenko Y, Maltsev P, Korepanov V, Molchanov O, Hayakawa H, Noda Y, Nagao T, Uyeda S (2004) ULF geomagnetic field measurements in Japan and some recent results associated with Iwateken Nairiku Hokubu earthquake in 1998. Phys Chem Earth 29:481-494

Hayakawa M (1999) Atmospheric and ionospheric electromagnetic phenomena associated with earthquakes. TERRAPUB, Tokyo

Liu JY, Chuo YJ, Shan SJ et al (2004) Pre-earthquake ionospheric anomalies registered by continuous GPS VTEC measurements. Ann Geophys 22:1585-1593

Macmillan S, Olsen N (2013) Observatory data and the Swarm mission. Earth Planets Space 65(11):1355

Maha Quassim S (2008) Inter-calibration between plasma instruments onboard DEMETER. Plasma Sci Technol 10:539. doi:10.1088/ 1009-0630/10/5/04

Parrot M (1994) Statistical study of ELF/VLF emissions recorded by a low-altitude satellite during seismic events. J Geophys Res 99:23339-23347

Pulinets SA (2004) Ionospheric precursors of earthquakes: recent advances in theory and practical applications. Terr Atmospheric Ocean Sci 15(3):413-435

Shen XH, Zhang XM, Wang LW et al (2011) The earthquake-related disturbances in ionosphere and project of the first China seismoelectromagnetic satellite. Earthq Sci 24(6):639-650

Zhu T, Wang LW (2011) LF electric field anomalies related to Wenchuan earthquake observed by DEMETER satellite. Chin J Geophys 54(3):717-727. doi:10.3969/j.issn.0001-5733.2011.03. 011 (in Chinese with English abstract) 